\title{
Possibilities and Perspectives of Applying the E-learning Model in Educational Institutions in Bosnia and Herzegovina
}

\author{
Dženana Rustempašić* and Aida Habul
}

School of Economics and Business, University of Sarajevo

\begin{tabular}{|c|c|}
\hline ARTICLE INFO & ABSTRACT \\
\hline $\begin{array}{l}\text { Keywords: } \\
\text { Artificial Intelligence } \\
\text { Digital Content } \\
\text { Digital Literacy } \\
\text { Online Platforms } \\
\text { Virtual Reality }\end{array}$ & $\begin{array}{l}\text { E-learning is a type of learning by using electronic technologies to } \\
\text { access an educational program outside of a traditional classroom. } \\
\text { As conventional classrooms continue to be transformed into digital, } \\
\text { it is necessary for teachers to deliver lectures through multiple } \\
\text { learning modes. Digitally enriched content and personal learning } \\
\text { should be the primary way of teaching, as well as collaborative and } \\
\text { interactive learning. The paper deals with issues of education in a } \\
\text { virtual environment, the role of virtual reality, and artificial } \\
\text { intelligence that is increasingly entering the classrooms of } \\
\text { developed countries. The paper explores what application of } \\
\text { artificial intelligence in the near future means for the development } \\
\text { and wider application of electronic learning in virtual classrooms } \\
\text { around the world, as well as in developing countries such as Bosnia } \\
\text { and Herzegovina. The paper presents the advantages and } \\
\text { opportunities that contribute to the improvement of e-learning in } \\
\text { educational institutions and the benefits for students and other } \\
\text { involved parties in the educational process, such as teachers and } \\
\text { parents. }\end{array}$ \\
\hline
\end{tabular}

\section{Introduction}

Although the idea of e-learning was still in its infancy in the sixties (this was a decade when PLATO, probably the first experiment in the world of e-learning was developed and first launched), Marshall McLuhan had a clear vision of the future of education. He believed that for better education, we need fewer teachers, more technology, and, most importantly, a more positive view of technology. As a historian by education, McLuhan noticed that education had not changed much in many aspects since finding the Gutenberg printing machine at the end of the 15th century. He considered that we should stop relying primarily on visual delivery methods and start creating a multi-sensory, interactive learning environment based on students' needs and interests (Taylor and Francis e / library, 2001).

E-learning primarily transmits education through computer and network of digital technology that includes the Internet, intranet, computer, satellite TV, CDROM, audio, and video resources. Therefore, e-learning can be broadly defined as the use of Information and Communication Technology or shortened ICTs to enhance and support learning that can range from teachers and learners using email for communication up to online courses.

\subsection{Artificial intelligence in the classroom}

Enhancing e-learning with a more comprehensive social experience enables learners to interact with each other as they would in the actual classroom. Students can complete group projects together, and hang out outside of the classroom, enriching their learning experience. 
Virtual reality already enhances certain aspects of e-learning. Companies, schools, and universities are experimenting with this new technology and are trying to understand how best to integrate virtual reality into curricula. Artificial intelligence is part of our everyday life and becomes more present in world classrooms.

By using tools such as Siri, Amazon, and Alexa, the possibilities of artificial intelligence in education are just beginning to be realized. While artificial intelligence will not wholly replace teachers, it is possible to transform the way teachers teach, and learners learn (The Tech Edvocate, 2017).

As artificial intelligence becomes significantly sophisticate then in the past, it would be possible for machines to read the expression on the face of the student, indicating that the machines are developing to the extent when they will be able to recognize the feelings of the person or the emotional state of the pupils. Thus, they will be able to modify the lesson in order to adapt it to the student's condition (Editors, 2018).

Machine learning algorithms have already begun to help teachers fill in knowledge gaps, pointing to subjects with which students have the most difficulty. Thanks to recent innovations in the field of artificial intelligence, almost the school, and the entire education system go through the same digital changes that are transformed by the world industry and business. Several studies predict that in the next ten years, artificial intelligence will replace teachers. Although such predictions are somewhat exaggerated, it is worth noting that the first tool that works on the principles of artificial intelligence and learning, IBM's Watson 1.0, has already found a way to world classrooms, where it has been proven as a teaching assistant and providing targeted support to teachers ( Expertsystem.com, 2018).

\subsection{Virtual school visits}

At the beginning of last year, US teachers received 55 million new students able to use new tools with the capability of capturing the attention of students and inspiring their imagination with the help of virtual reality. Hundreds of new intriguing experiences, many of which are free, can transfer students back through history or our solar system without a magical school bus (Babich, 2019).

From the War of Independence that took place in the United States to the marshes of the Jura geological period, students can find themselves at the center of the action where they can experience their own real experience. The full range of school virtual and extended experiences has been developed for subjects ranging from mathematics, through history to foreign languages (Samit, 2017).

These virtual adventures can be embedded in the emotional center of the human brain by misleading the mind to believe that users are really "teleported" out of the classroom into an environment that fully occupies their senses. Research has already shown that we remember only $10 \%$ of the read, $20 \%$ of what we hear, and $30 \%$ of what we hear and see together. However, a virtual reality can deceive the brain's core so that it can feel that a dinosaur or emotional depression is being haunted by life in a refugee camp. The joy of walking on the moon's surface or passing through the deadly trenches of the First World War can trigger an emotional reaction deeper than any film. According to a scientific study of biometric monitoring of the eye movement and direction of view, electrodermal reaction and heart rate, $27 \%$ of users of the virtual reality were more emotionally involved in these contents than those available through a two-dimensional, conventional video (Horton W. \& Horton K ., 2003).

\section{Methodology}

Unlike some European countries or the United States of America, there are still no clearly defined e-learning strategies in Bosnia and Herzegovina, and instances of using online 
learning are only sporadic and more experimental. They can only be assessed as attempts by individual schools to use Google Education, free online learning platforms, in a short period of time (during one week in November specifically). Since the implementation of e -learning is only in its infancy stage in the country; research that evaluates the success of the application of this model in our educational system is based on determining existing conditions in educational institutions in regard of usage of IT in today's classrooms and perspectives for the implementation of e-learning model. Indeed, in this light, the implementation of some of the modern forms of learning would be a significant step. Attitudes of primary stakeholder groups for this venture were examined with the overall goal to form an e-learning model that would have a realistic prospect of success.

To examine how e-learning service is applied, a base of 20 particles (claims) was formed in this case for high school students. For the first part of the e-learning attitude questionnaire, four particles were selected, which answer questions related to teacher-student interaction. In the second part of the e-Learning attitudes questionnaire, four particles were also selected that relate to students' prior experience. The third part shows the 12 particles concerning the cost of learning in a virtual learning environment as well as the students' experiences related to the virtual learning environment. Responses to the particles in this group are shown on a Likert scale of estimates from one to five, where rating 1 corresponds to the "disagree" category; 2 "I disagree"; 3 - "neither agree nor disagree"; 4 - "I agree" and the assessment of 5 categories "I completely agree".

The first part of the questionnaire covers information about respondents' computer usage habits, such as questions about the frequency of computer use, while the other two questions relate to knowing the meaning of e-learning and attending e-courses. The respondents got familiar with the purpose of the survey and the process of completing the questionnaire. All respondents filled in the questionnaire voluntarily, independently and anonymously, and the estimated time to complete the questionnaire was ten minutes. Exploratory factor analysis, a principal component analysis method, was used to determine the validity of the questionnaire. Attitude towards e-learning is determined by adding up the value of the response to the statements and is expressed by the number of points. If the student responded to the assertion with a grade of five, then 'I agree,' five points were awarded, and one up to one, 'one at all,' where one point was awarded.

\section{Results and discussion}

The survey provides an analysis of potentials for e-learning model implementation in secondary schools in Bosnia and Herzegovina and other educational institutions, as well as the ability to define and create a national e-learning strategy. The survey was focused on collecting information necessary for creating the adoption of e-learning model in secondary schools in Bosnia and Herzegovina. Survey respondents were students aged 16-19, both sexes.

Table 1. shows the factor structure of the particles, with the values of the characteristic root and the percentage of the explained variance of each component. Given the content of the particles and their projections on the components, the first component corresponds to the interaction of teachers and students, the other component corresponds to the benefits that students have from the virtual learning environment, and the third corresponds to the economic aspect (costs for individual students and the scope of work). 
Table 1

The factor structure of the particles

\begin{tabular}{|c|c|c|c|}
\hline & \multicolumn{3}{|c|}{ Components } \\
\hline & 1 & 2 & 3 \\
\hline 20. VLE helps the professor to respond to individual learning needs. & .722 & .271 & -.142 \\
\hline 19. VLE supports a close relationship between students and instructors. & .718 & .240 & -.004 \\
\hline $\begin{array}{l}\text { 18. VLE enables professors to provide students with different sources of } \\
\text { learning.online učionici. }\end{array}$ & .657 & .296 & .235 \\
\hline $\begin{array}{l}\text { 17. VLE increases the level of interaction between individual students and } \\
\text { instructors }\end{array}$ & .579 & .295 & .037 \\
\hline 16. VLE helps professors to be available to students outside the classroom & .515 & .253 & .153 \\
\hline 15. VLE increases student workload. & .228 & .768 & .084 \\
\hline 14. VLE increases costs for individual students (printing). & .220 & .709 & .059 \\
\hline 13. VLE helps students prepare well for lectures in an online classroom. & .203 & 613 & .126 \\
\hline 12. VLE provides greater transparency for individual learning. & .410 & .606 & -.037 \\
\hline $\begin{array}{l}\text { 11. VLE provides students with flexibility in terms of their educational needs } \\
\text { (offering access to materials at any time - allowing them to study when they have } \\
\text { time). }\end{array}$ & .409 & .566 & -.133 \\
\hline $\begin{array}{l}\text { 10. VLE increases opportunities for discussion and debate among students outside } \\
\text { the classroom. }\end{array}$ & .128 & -.238 & -.816 \\
\hline 9. VLE supports the exchange of ideas and experiences among students. & 449 & -.217 & 630 \\
\hline Characteristic root & 4.414 & 1.184 & 1.003 \\
\hline$\%$ of the explained variance & 23.01 & 21.91 & 10.067 \\
\hline
\end{tabular}

Source: Author's work

In order to test the multidimensionality of the instrument, an analysis of the main components was carried out. In order to check that correlation matrices are suitable for carrying out factor analysis, we have conducted the Kaiser-Meyer-Olkin test and the Bartlett test. The KaiserMeyer-Olkin test shows the proportion of variance that is common or can be explained by latent factors. When the value of this test is more significant than 0.60 , we consider that our data is suitable for carrying out factor analysis. In our case, the value is 0.870 . The Bartlett test checks if our matrix is identical to the identity matrix. If our matrix were identical to the identity matrix, this would mean that the matrix variables were unconnected and would not make sense to carry out a factor analysis.

This test must be significant with at least $95 \%$ security in order for our data to be comparable to factorization. In our case, the approximate $\chi^{2}$ is 442,256 and is significant at $99,9 \%$. The results of these tests on our data indicate that it is justifiable to carry out a factor analysis. Analysis of the main components resulted in a three-factor solution. The characteristic roots of the three components are more significant than one, and together, they explain $55 \%$ of the variance.

Analysis of results proves the assumption that VLE increases the opportunities for discussion and debate among students outside the class. Results show that $71 \%$ of students agree with the claim that VLE provides students with flexibility in terms of their educational needs (offering access to materials always and anywhere - allowing them to study when they have time. It allows them to access a variety of content that they do not have access to in traditional classrooms. They learn how to use information responsibly and transparently. Furthermore, it enables them to access the same online content as other students who are not restricted by the national curriculum, which are not adapted to constant changes in the 
external environment. Changes in the environment might impose school management to entail policies that would bring necessary changes in terms of adaptability, possession of skills and knowledge in the use of communication tools and software that have become standards in the digital age. Students can spend more time working on materials in order to improve their results, which is considered useful because they have more time to think and connect previous knowledge with newly learned topics. Survey results showed that online tools used in asynchronous e-learning allow two-way communication between learners and teachers, or multi-modal, collaborative communication among students themselves. However, $55.8 \%$ of respondents agree that VLE increases the scope of students' work.

Dimensionality was added to the correlation matrix, meaning that underlying components could be identified in the subjects' answers. The logical and content analysis of the particles indicates that the first component corresponds to the quality of the student-teacher interaction. The second component corresponds to the assessment of the user that the virtual environment has for learning and students, while the third one corresponds to the economic aspect of the virtual learning environment (VLE).

The economic aspect, in this case, relates not only to money but also to invested labor. If we look at the claim instrument, we see that one particle indicates an increase in student workload since the student initiates discussions and communication with both teachers and other students, which is not the case in a traditional classroom where a complete lesson is pre-planned and organized by the teacher and the Ministry of Education. Since three factors or three constructs or three variables were obtained, it was interesting to examine the correlation between these three constructs and the other claims in the matrix table. A statistically significant correlation was found between particles related to previous experience that students had in the virtual learning environment. A statistically significant correlation was found between the first and second group questions on the level 0.05 or $p<0.05$

There is a high correlation of 0.069 between the teacher-student components and the benefits of the virtual learning environment at the 0.01 level. It was expected that the correlation is high; that is, the teacher is an essential factor in the teaching process and that it contributes to better interaction in the educational process. It is essential for the individual student that ongoing daily interaction with teachers is maintained. The student perceives that the virtual learning environment gives them more opportunities to access a myriad of information, more frequent contact with the instructor or teacher, which allows him to ask questions in constant communication, which is not common practice in the traditional classroom environment.

Thanks to online learning, students in the most impoverished cities or smaller towns can use the same educational resources as students in world capitals and large western cities, all thanks to online lectures at affordable rates. The e-Learning Initiative implies ensuring the right to education and reducing costs to such an extent that it becomes accessible to the developing country and countries in transition, such as Bosnia and Herzegovina.

Some of the disagreements on the way to implementing online learning is to adapt to elearning education, due to the inability of regular access to high-speed Internet and educated IT educators. Another obstacle that the country could face in the process of improving the education system is the initial cost of e-learning. Within an extended group of claims, all particles are significant. There was also a statistically significant correlation between particles related to previous experiences that students had in the virtual learning environment, meaning that positive learning experiences and communication in the virtual learning environment influenced students' preferences and their choice of modalities of learning. Knowledge is acquired in space, time, and opportunities for personal growth and development.

Students, when asked on issues concerning the virtual learning environment and the application of e-learning tools, have confirmed that e-learning offers opportunities to acquire knowledge and skills that are not available in the schools they attend. 
Possibilities offered by e-learning go beyond the traditional curriculum framework and the law-imposed curriculum that does not accompany changes in the environment, and accordingly adapts the curricula, subjects, and interests of students towards training in the digital age, in which some other skills and knowledge are desirable.

\section{Conclusion}

The e-learning model currently used in educational institutions in Bosnia and Herzegovina is a hybrid model, that is, a combination of traditional learning and online learning in its infancy. The essential strategy that could support e-learning model adoption is the strategy that ensures the implementation of e-learning programs in phases, so the first phase of strategy implementation include the adoption of a blended learning model first given the current state of the country economy. Additionally, funding and support of technical staff is another critical aspect of the application of the -learning model in the country. For successful implementation of the e-learning model, specific criteria should be developed, such as the acquisition of appropriate technological infrastructure and adequate educational content developed by teachers who possess information skills followed by a developed culture that fosters learning and knowledge sharing in a virtual environment.

Students enrolled in this research have a highly positive attitude towards e-learning, which leads to the conclusion that students are willing to learn using IT solutions in the classroom. The organization of the online program and online classes enable students to access content and fulfill tasks according to their time organization. Most students use the Internet every day and communicate with social networks, which undoubtedly contribute to their readiness to accept new IT solutions in the learning process. Therefore, the differences in attitudes towards e-learning are also related to the purpose and frequency of using the Internet.

Possible obstacles that may affect the implementation of e-learning adoption in educational institutions in Bosnia and Herzegovina are the high cost of internet equipment (infrastructure), the high cost of software or an appropriate computer program, lack of knowledge in computer science and Internet usage along with fear of failure to offer elearning services. Educational institutions, as well as other relevant government institutions, should undoubtedly pay attention to the growing needs of young people who have expressed the need for an e-learning model that is not currently being actively and regularly implemented in schools. According to the results of this research, it has been determined that several factors hinder the widespread use of new learning technologies, including access to information and communication technologies in schools that are inadequate and uneven, with a somewhat better situation in urban areas. There is also a lack of capacity to utilize available technology since most of the teachers lack the necessary skills for the smooth implementation of the e-learning model. One of the main disadvantages of using the e-learning model is that it still heavily relies on social support in the sense that e-learning depends on teacher's ability and readiness to create and prepare course materials and use online educational tools.

Adopting e-learning model by students in the educational system is conditioned by follow selecting an appropriate online e-learning platform that will offer the necessary tools for elearning model implementation and designing a virtual learning environment that will allow students to access educational content and communicate with teachers and other students easily.

\section{References}

Babich, N., 2019. How VR Education Will Change How We Learn \& Teach | Adobe XD Ideas. [online] Ideas. Available at: <https://xd.adobe.com/ideas/principles/emergingtechnology/virtual-reality-will-change-learn-teach

Backer, L. (2017). The Changing Face of Markets in Education: Competition for Online 
Education and Education Hubs. [online] Lcbackerblog.blogspot.com. Available at: http://lcbackerblog.blogspot.com/2012/06/from-online-universitiescom-eight.html

Brusilovsky, P. and Miller, P. (2001). "Course Delivery Systems for the Virtual University," In Access to Knowledge: New Information Technologies and the Emergence of the Virtual University,

CloudShare. (2019). Virtual Learning - Everything You Need to Know | CloudShare. [online] Available at: https://www.cloudshare.com/blog/cloudshare/blogvirtual-learning-everythi ng -you-need-to-know [Accessed 5 Mar. 2019].

Coache.gse.harvard.edu. (2019). Inside Higher Ed: "Less Is More". [online] Available at: https://coache.gse.harvard.edu/news/less-more [Accessed 2 Feb. 2019].

Dillenbourg, P., D.K. Schneider, and P. Synteta.(2002) "Virtual Learning Environments." Proceedings of the 3rd Hellenic Conference "Information \& Communication Technologies in Education."

Dumford, A., and Miller, A. (2018). Online learning in higher education: exploring advantages and disadvantages for engagement. Journal of Computing in Higher Education, 30(3), pp.452-465.

Editors, T., 2018. NEWS \& TRENDS: How Is AI Used in Education-Real World Examples Of Today And A Peek Into The Future. [online] TechLearningMagazine. Available at: $<$ https://www.techlearning.com/features/news-and-trends-how-is-ai-used-ineducationreal-world-examples-of-today-and-a-peek-into-the-future

eLearning Industry. (n.d.). The History of Distance Learning - Infographic - eLearning Industry. [online] Available at: https://elearningindustry.com/the-history-of-distancelearning-infographic [Accessed 1 Mar. 2019].

Files.eric.ed.gov. (2001). [online] Available at: https://files.eric.ed.gov/fulltext/ED491391 .pdf [Accessed 31 Mar. 2019].

Fortune. (2018). http://fortune.com. [online] Available at: http://fortune.com/2015/04/25/ augmented-reality-virtual-reality/ [Accessed 31 Mar. 2019].

Gaml.uis.unesco.org. (2018). [online] Available at: http://gaml.uis.unesco.org/wpcontent/uploads/sites/2/2018/10/ip51-global-framework-reference-digital-literacy-skills2018-en.pdf [Accessed 1 Mar. 2019].

Google for Education. (2019). Bring your lessons to life with Expeditions | Google for Education. [online] Available at: https://edu.google.com/products/vr-ar/expeditions/

Google for Education. (2019). Solutions built for teachers and students | Google for Education. [online] Available at: https://edu.google.com/ [Accessed 30 Mar. 2019].

Hartshorne, R., and Ajjan, H. (2009). Examining student decisions to adopt Web 2.0 technologies: theory and empirical tests. Journal of Computing in Higher Education, 21(3), pp.183-198.

Herder, E. Dimitrova VG, Sosnovsky, S. (2017) Adaptive Intelligent Learning Environments, Technology Enhanced Learning, Research Themes, Springer International Publishing

Hope, J. (2018). Personalize online learning for a high-quality learning experience. Recruiting \& Retaining Adult Learners, 20(12), pp.12-12.

Ieeexplore.ieee.org. (2018). Assisted Technological Headset using Internet of Things - IEEE Conference Publication. [online] Available at: https://ieeexplore.ieee.org/document 
Kurt, S. (n.d.). Educational Technology - International Society for Educational Technology. [online] Educational Technology. Available at: https://educationaltechnology.net/ [Accessed 31 Mar. 2019].

Opentextbc.ca. (n.d.). A short history of educational technology, "Teaching in a Digital Age. [online] Available at: https://opentextbc.ca/teachinginadigitalage/chapter/section-8-1-ashort-history-of-educational-technology/ [Accessed 31 Mar. 2019].

Rosenberg, M., and Foshay, R. (2002). E-learning: Strategies for delivering knowledge in the digital age. Performance Improvement, 41(5), pp.50-51.

Rossett, A., and Sheldon, K. (2001). Beyond the podium. San Francisco (CA): JosseyBass/Pfeiffer.

Sharma, A. (2017). The History of Distance Learning and the LMS. [online] eLearn Hub. Available at: http://elearnhub.org/the-history-of-distance-learning-and-the-lms/

Taylor and Francis e/library (2001). The master of implosion.

The Tech Edvocate. (2019). The Tech Edvocate - Authoritative EdTech News \& Commentary. [online] Available at: https://www.thetechedvocate.org/ 